\title{
Aptamer-polymer functionalized silicon nanosubstrates for enhanced recovered circulating tumor cell viability and in vitro chemosensitivity testing
}

\author{
This article was published in the following Dove Press journal: \\ International Journal of Nanomedicine \\ 18 May 2016 \\ Number of times this article has been viewed
}

\author{
Qinglin Shen ${ }^{1,2, *}$, Caixia \\ Peng ${ }^{2,3, *}$, Yan Zhan', Liang Fan', \\ Mengyi Wang', Qing Zhou', Jue \\ Liu $^{2,4}$, Xiaojuan Lv', Qiu Tang', \\ Jun $\mathrm{Li}^{1,2}$, Xiaodong Huang ${ }^{2}$, \\ Jiahong $\mathrm{Xia}^{2}$ \\ 'Department of Oncology, ${ }^{2}$ Key \\ Laboratory for Molecular Diagnosis \\ of Hubei Province, ${ }^{3}$ Central \\ Laboratory, ${ }^{4}$ Department of Pharmacy, \\ The Central Hospital of Wuhan, Tongji \\ Medical College, Huazhong University \\ of Science and Technology, Wuhan, \\ People's Republic of China \\ *These authors contributed equally \\ to this work
}

\begin{abstract}
Selection of the optimal chemotherapy regimen for an individual cancer patient is challenging. The existing chemosensitivity tests are costly, time-consuming, and not amenable to wide utilization within a clinic. This limitation might be addressed by the recently proposed use of circulating tumor cells (CTCs), which provide an opportunity to noninvasively monitor response to therapy. Over the past few decades, various techniques were developed to capture and recover CTCs, but these techniques were often limited by a capture and recovery performance tradeoff between high viability and high efficiency. In this work, we used anti-epithelial cell adhesion molecule coated aptamer-poly ( $\mathrm{N}$-isopropylacrylamide) functionalized silicon nanowire substrates to capture and release epithelial cell adhesion molecule-positive CTCs at $32^{\circ} \mathrm{C}$ and $4^{\circ} \mathrm{C}$, respectively. Then, we applied the nuclease to digest the aptamer to release the captured CTCs (near or at the end of the polymer brush), which cannot be released by heating/ cooling process. High viability and purity CTCs could be achieved by decreasing the heating/ cooling cycles and enzymatic treatment rounds. Furthermore, the time-saving process is helpful to maintain the morphology and enhance vitality of the recovered CTCs and is beneficial to the subsequent cell culture in vitro. We validated the feasibility of chemosensitivity testing based on the recovered HCC 827 cells using an adenosine triphosphate-tumor chemosensitivity assay, and the results suggested that our method can determine which agent and what concentration have the best chemosensitivity for the culturing recovered CTCs. So, the novel method capable of a highly effective capture and recovery of high viability CTCs will pave the way for chemosensitivity testing.
\end{abstract}

Keywords: circulating tumor cells, aptamer-PNIPAM coating, capture and recovery, cell culture in vitro, chemosensitivity testing

\section{Introduction}

Chemotherapy is one of the major treatment methods against malignant tumors. With the ever-increasing number of drugs approved to treat cancers, selection of the optimal treatment regimen for an individual patient is challenging. Clinical oncologists weigh the potential benefits of the drugs against the side effects to the patient. To avoid blind chemotherapy and to improve the therapeutic effect, we need rapid and reliable detection technologies and methods for chemosensitivity testing. Currently, the existing chemosensitivity tests, including the human tumor clonogenic assay, 3-(4,5-dimethyl2-thiazolyl)-2,5-diphenyl-2 H-tetrazolium bromide assay, histoculture drug response assay, and collagen gel-droplet-embedded-culture drug sensitivity test, are costly, 
time-consuming, tumor type-specific, and not amenable to most cancers. ${ }^{1}$ The existing chemosensitivity tests include the human tumor clonogenic assay, 3-(4,5-dimethyl-2thiazolyl)-2,5 -diphenyl-2 H-tetrazolium bromide assay, histoculture drug response assay, and collagen gel-dropletembedded-culture drug sensitivity test.

This limitation might be overcome by the recently proposed use of circulating tumor cells (CTCs) as a "liquid biopsy". ${ }^{2,3} \mathrm{CTCs}^{4-6}$ are defined as cancer cells that break away from either the primary tumors or its metastases, and CTCs have been detected in the peripheral blood of patients with solid tumors. CTCs provide an opportunity to noninvasively monitor cancer patients' prognosis and response to therapy. Over the past few decades, although great endeavor has been devoted to developing CTC capture and recovery devices in which captured cells are released usually under certain special stimuli (such as light, electric current, enzymes, temperature, and $\mathrm{pH}),{ }^{7-11}$ these techniques are often limited by a capture and recovery performance tradeoff between high efficiency and high viability. Hence, there is a desperate need for techniques to capture and recover high viability CTCs.

Previously, a study of a highly efficient and inexpensive CTC assay ${ }^{12}$ has reported that it can enrich, identify, and enumerate CTCs in whole-blood samples collected from cancer patients based on anti-epithelial cell adhesion molecule (antiEpCAM) ${ }^{13}$-coated silicon nanowire substrates (SiNWS). To improve CTC capture efficiency, the researchers combined the SiNWS with a polydimethylsiloxane (PDMS)-based chaotic mixer ${ }^{14}$ that enhances contact frequency between flow-through CTCs and the substrate. To further improve the cell-release performance, they grafted thermoresponsive polymer brushes onto SiNWS. Thermoresponsive SiNWS can capture and release CTCs at $37^{\circ} \mathrm{C}$ and $4{ }^{\circ} \mathrm{C}$, respectively. ${ }^{7}$ The temperature-dependent conformational changes of polymer brushes can alter the accessibility of the capture agent (eg, anti-EpCAM) on the SiNWS. We also developed a platform that is capable of not only capturing CTCs with high efficiency but also recovering the CTCs with high purity and viability upon two rounds of nuclease treatment. ${ }^{8}$ Although efficient and reproducible enumeration of CTCs has been achieved, the several heating/cooling process cycles or multiple rounds of enzyme treatment may affect the recovery cell morphology and viability; one of the remaining obstacles is to minimize damaged cells and improve cell viability performance.

Therefore, based on our previous studies, ${ }^{7,8}$ we anticipated that further improvement of cell viability performance could be achieved by decreasing the heating/cooling cycles and enzymatic treatment rounds. Thermoresponsive poly
(N-isopropylacrylamide) (PNIPAM) $)^{15-20}$ is one of typical thermosensitive polymers with a good biocompatible and a lower critical solution temperature behavior approximately $32^{\circ} \mathrm{C}$ in an aqueous solution, which is close to the physiological temperature, so PNIPAM is widely applied to the bioseparation. The PNIPAM exhibits hydrophilic characteristics below the lower critical solution temperature, but hydrophobic above the lower critical solution temperature. As we know, aptamers ${ }^{21,22}$ are single-stranded DNA or RNA oligonucleotides that fold into specific 3D structures and are screened by the Systematic Evolution of Ligands by Exponential Enrichment procedure. Because of their stability, lack of immunogenicity, and ready availability, aptamers have been developed against a variety of targets, including extracellular ligands and polymers. ${ }^{23-26}$ Aptamers can be digested by nucleases, and so we can release captured cells by enzyme treatment. Therefore, we speculated that the aptamer-polymer conjugation could be utilized as a strategy to mediate highly effective capture and recovery $\mathrm{CTCs} .{ }^{26}$ By grafting thermoresponsive PNIPAM brushes onto SiNWS, and then we conjugated the biotin-aptamer to PNIPAM surface, the sandwich structure Aptamer-PNIPAM-SiNWS was denoted as Ap-P-SiNWS. The Ap-P-SiNWS can capture and release CTCs at $32^{\circ} \mathrm{C}$ and $4^{\circ} \mathrm{C}$, respectively, and the rest of the CTCs, which are near or at the end of the polymer brush and cannot be released by heating/cooling, can be further released by the nuclease digestion (Figure 1A). We showed that our Ap-P-SiNWS could be utilized to capture and recover CTCs from both artificial and clinical blood samples, enabling subsequent cell culture in vitro. The significant advantages of our approach are the use of aptamer-PNIPAM functionalized SiNWS: the high viability and purity CTCs can be achieved by one cycle heating/cooling process and one round enzyme treatment. Most importantly, the time-saving process is helpful to maintain the morphology and vitality of the recovered CTCs and is beneficial to the subsequent cell culture in vitro. We validate the feasibility of chemosensitivity testing based on the recovered HCC827 cells using an adenosine triphosphate-tumor chemosensitivity assay (ATP-TCA), ${ }^{27}$ and our method can determine which agent and what concentration have the best chemosensitivity for the culturing of recovered CTCs. The novel method capable of high effective capture and recovery of high viability CTCs will pave the way for chemosensitivity testing based on CTCs.

\section{Materials and methods Materials}

Silicon wafers (p-type, (100)-orientation, resistivity of $\sim 10-20 \Omega 3 \mathrm{~cm}$ ) were acquired from Silicon Quest 
A

Anti-EpCAM present at $32^{\circ} \mathrm{C}$

Anti-EpCAM internalized at $4^{\circ} \mathrm{C}$

Aptamer digested by enzyme
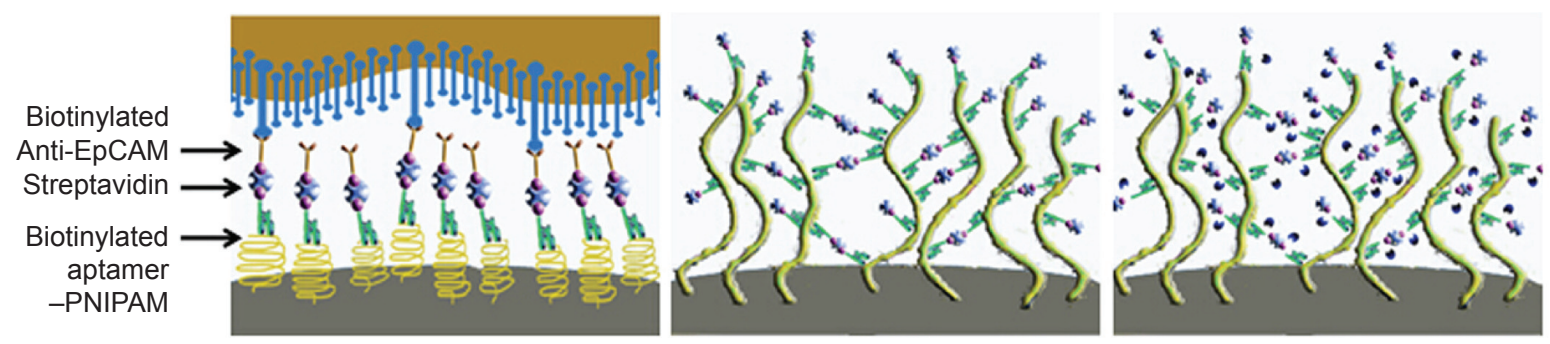

B

CTC capture at $32^{\circ} \mathrm{C}$

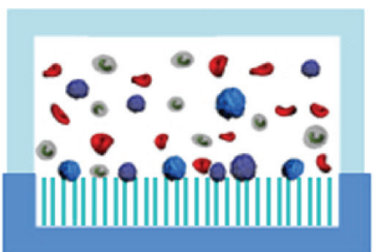

CTC release at $4^{\circ} \mathrm{C}$
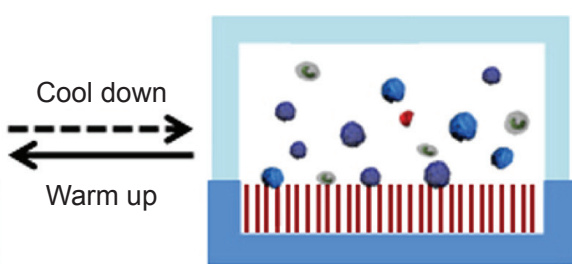

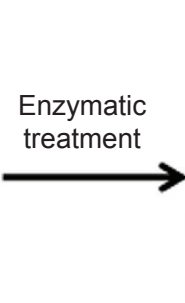

CTC release by enzyme

Figure I A schematic diagram of the capture and release of CTCs from the Ap-P-SiNWS chip.

Notes: (A) Conceptual illustration of the molecular mechanism for the capture and release of CTCs from the Ap-P-SiNWS by heating/cooling process and enzymatic treatment. (B) A schematic diagram of capture and release of CTCs from the Ap-P-SiNWS chip upon heating/cooling process and enzyme digestion.

Abbreviations: Ap-P-SiNWS, aptamer-PNIPAM-SiNWS; CTC, circulating tumor cell; EpCAM, epithelial cell adhesion molecule; PNIPAM, poly (N-isopropylacrylamide); SiNWS, silicon nanowire substrates.

Int. (San Jose, CA, USA). Sulfuric acid (98\%), hydrogen peroxide $(30 \%)$, silver nitrate $(>99.8 \%)$, hydrofluoric acid (48\%), ethanol (>99.5\%), and 3-mercaptopropyl trimethoxysilane (95\%) were purchased from SigmaAldrich Co. (St Louis, MO, USA). Anhydrous toluene, dichloromethane, $\mathrm{N}$-dimethylformamide, triethylamine, 3-aminopropyltrieth-oxysilane (98\%), and 2-aminoethylmethacrylate hydrochloride were obtained from SigmaAldrich. N-isopropylacrylamide ( $>98.0 \%$ ) was purchased from TCI America (San Francisco, CA, USA). All chemicals were used without additional purification. Non-small-cell lung cancer cell line (HCC827), cervical cancer cell line (HeLa), prostate cancer cell line (PC3), glioblastoma cell line (U87), and acute T Cell Leukemia cell line (Jurkat) were purchased from American Type Culture Collection (Manassas, VA, USA). White blood cells (WBCs) were isolated from blood samples collected from healthy donors. The biotinylated DNA aptamer ${ }^{8}$ (sequence, Ap: biotin5'-TTTATGGGTGGGTGGGGGGTTTTT-3': 24 bp) was custom synthesized by Sangon Biotech Co., Ltd (Shanghai, People's Republic of China). GlutaMAX-I, Roswell Park Memorial Institute medium 1640 (RPMI-1640) culture medium, 4'6-diamidino-2-phenylindole (DAPI), Vybrant DID, and DIO cell-labeling solutions were obtained from Thermo Fisher Scientific (Waltham, MA, USA). Biotinylated human anti-EpCAM/TROP1 antibody (goat IgG) and streptavidin $(1 \mathrm{mg} / \mathrm{mL})$ were obtained from $\mathrm{R} \& \mathrm{D}$ Systems, Inc. (Minneapolis, MN, USA). Fetal bovine serum was obtained from Lonza BioWhittaker (Walkersville, MD, USA).
Sodium citrate $(10 \% \mathrm{w} / \mathrm{w}$, Sigma-Aldrich) was used to avoid coagulation during blood collection. Acridine orange/ ethidium bromide (AO/EB) was obtained from Invitrogen and used for dual-fluorescent cell viability assay. One microliter of AO stock $(5 \mathrm{mg} / \mathrm{mL}$ in ethanol) and $1 \mu \mathrm{L}$ of EB stock ( $3 \mathrm{mg} / \mathrm{mL}$ in ethanol) were mixed together in $1 \mathrm{~mL}$ of phosphate-buffered saline (PBS) as AO/EB working solution. Tris-HCl buffer and ATP-TCA kit were purchased from Huzhou Haichuang Biotech Co., Ltd. (Huzhou, Zhejiang, People's Republic of China).

\section{Preparation of biotin-aptamer-PNIPAM functioned SiNWS}

The assumption is to covalently graft thermally responsive polymer brushes, PNIPAM, onto SiNWS by a surface initiated atom-transfer radical polymerization. ${ }^{28}$ In these polymer brushes, we strategically introduced covalentlylinked biotin-aptamer and formed biotinylated Ap-PSiNWS (biotin-Ap-P-SiNWS). The biotin-Ap-P-SiNWS were prepared through three continuous steps as illustrated in Figure 2, including 1) photolithography and wet etching to introduce vertically aligned SiNWS onto a silicon wafer (Figure S1A); 2) covalently grafting PNIPAM polymer brushes that confer "thermoresponsiveness" to the devices; and 3) biotin-aptamer was then conjugated to the free amino groups of these polymer brushes to yield the desired biotin-Ap-P-SiNWS. The biotin-streptavidin-mediated conjugation was employed to introduce NSCLC CTCspecific capture agent (eg, anti-EpCAM) onto SiNWS. For 


\section{Preparation of biotin-aptamer-PNIPAM functioned SiNWS (biotin-Ap-P-SiNWS)}

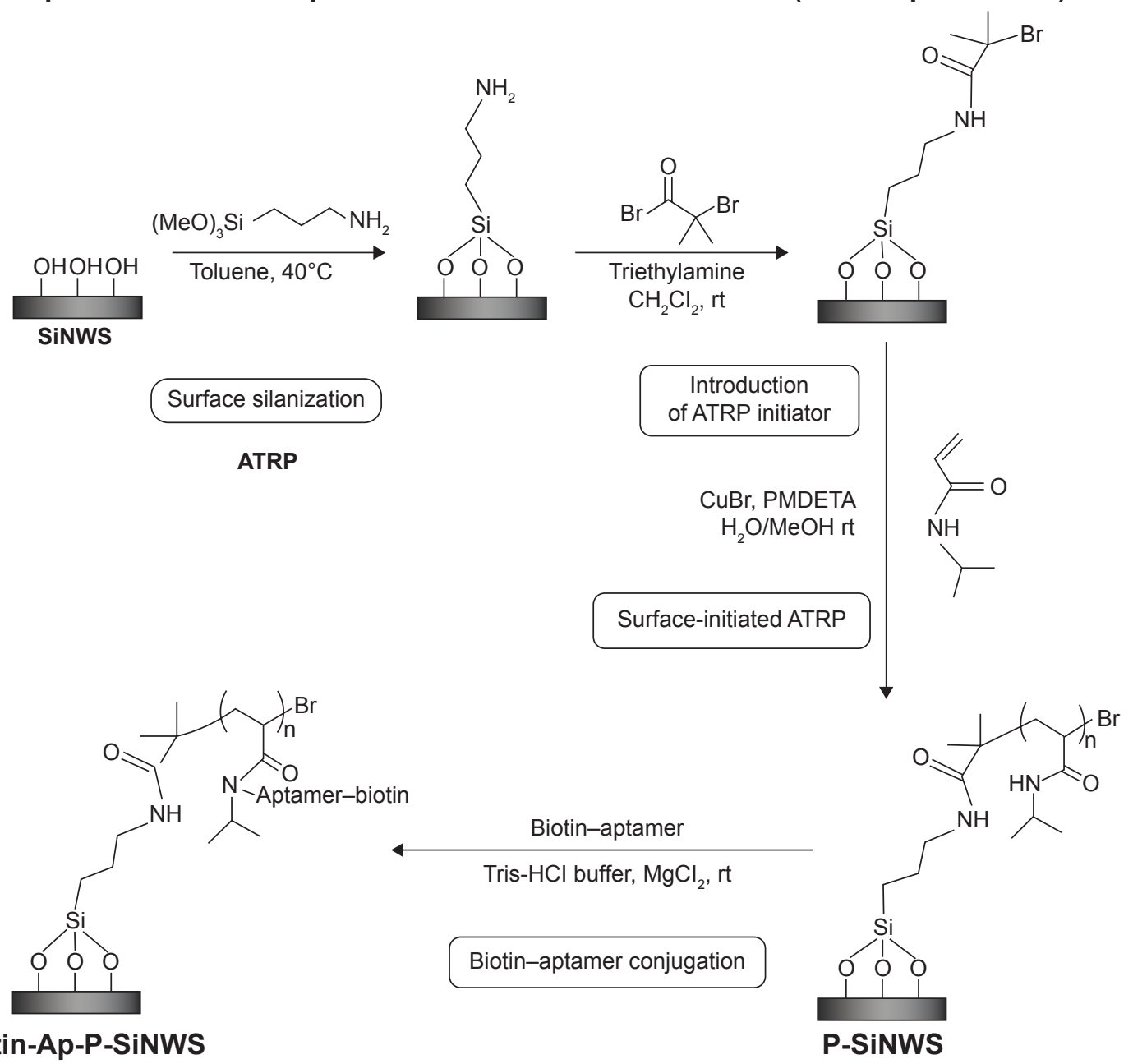

Figure 2 Synthetic approach employed to covalently graft biotinylated aptamer-PNIPAM onto SiNWS (biotin-Ap-P-SiNWS).

Abbreviations: Ap-P-SiNWS, aptamer-PNIPAM-SiNWS; P-SiNWS, PNIPAM-SiNWS; PMDETA, N,N,N',N",N"-pentamethyldiethylenetriamine; ATRP, atom transfer radical polymerization; PNIPAM, poly ( $\mathrm{N}$-isopropylacrylamide); rt, room temperature; SiNWS, silicon nanowire substrates.

the surface characterizations of biotin-Ap-P-SiNWS refer to Figure S1B.

\section{Modification of the biotin-Ap-P-SiNWS chips with streptavidin}

Chip holder is employed to assemble a patterned Ap-PSiNWS chip with an overlaid PDMS chaotic mixer. The Ap-P-SiNWS chip was then rinsed once with $200 \mu \mathrm{L}$ PBS at room temperature, and subsequently the surface of the chip was modified with $250 \mu \mathrm{L}$ streptavidin $(50 \mu \mathrm{g} / \mathrm{mL})$ at $4^{\circ} \mathrm{C}$ overnight. Then, the Ap-P-SiNWS chip was washed thrice with $250 \mu \mathrm{L}$ PBS. Next, the chip was treated with $250 \mu \mathrm{L}$ PBS solution of anti-EpCAM $(10 \mu \mathrm{g} / \mathrm{mL})$ at room temperature for 2 hours, and then flushed with $250 \mu \mathrm{L}$ PBS to remove excess anti-EpCAM. The chips were stored at $4{ }^{\circ} \mathrm{C}$ ready for subsequent cell capture and release.

\section{Biotin-Ap-P-SiNWS device captures and releases CTCs}

As shown in Figure 1, the biotin-Ap-P-SiNWS underwent reversible switches between hydrophobic and hydrophilic surfaces at $32^{\circ} \mathrm{C}$ and $4^{\circ} \mathrm{C}$, respectively. The surfaces became hydrophilic at $32^{\circ} \mathrm{C}$, and the capture agent (eg, biotinylated anti-EpCAM) through biotin-streptavidin interaction can be introduced onto the substrates, enabling a highly efficient CTC capture. When the temperature is reduced to $4^{\circ} \mathrm{C}$, the backbones of substrate-grafted PNIPAM undergo conformational changes, leading to an internalization of anti-EpCAM embedded inside the elongated polymer brushes. As a result, the nanosubstrate-immobilized CTCs are effectively released. Subsequently, we used the nuclease to digest the aptamer and release the cells near or at the end of these polymers brush (Figure 1A). The high viability 
CTCs and high release efficiency could be achieved by sequential heating/cooling process and enzymatic treatment (Figure 1B).

\section{Immunofluorescence staining of captured CTCs}

CTCs captured with the Ap-P-SiNWS chips were fixed with PBS containing 2.0\% formaldehyde, washed, and blocked with $1 \%$ donkey sera in PBS. Then, cells were identified with a commonly used three-color immunofluorescence method, including fluorescein isothiocyanate (FITC)-labeled antiEpCAM, a marker for epithelial cells, Cy5-labeled anti-CD45 (CD45, a marker for WBCs), and DAPI nuclear staining. Combined information was utilized to discriminate tumor cells from WBCs. Cells that were Cy5+/FITC-/DAP+ and morphologically intact were identified as CTCs, while cells that exhibited high FITC and low Cy5 expression levels were WBCs.

\section{Test the viability of recovered CTCs and culture in vitro}

The ethics committee of the Central Hospital of Wuhan of Tongji Medical College of Huazhong University of Science and Technology approved the study. Written informed consent obtained from all donors. An amount of $1.0 \mathrm{~mL}$ of whole blood samples from healthy donors spiked with known numbers of cancer cells or $1.0 \mathrm{~mL}$ blood samples donated by cancer patients with lung cancer was used in our experiments. Red blood cells were removed using red blood cell lysis buffer. Then, we introduced the treated blood samples to the Ap-P-SiNWS chips for capturing and releasing. The released cells could be collected from the Ap-P-SiNWS chips by PBS washing. To examine the viability of tumor cells after being captured and then released from one cycle heating/cooling process and one round enzyme digestion by our Ap-P-SiNWS chips, we carried out the study of a dual-fluorescence viability assay (AO/EB staining). "AO-green staining” indicates live cells and "EB-red staining" indicates dead cells. Cells were then observed under a confocal laser scanning microscopy (Olympus X81; Olympus, Tokyo, Japan). For further cell culture, the recovered HCC 827 cells in suspension were first centrifuged and washed with $200 \mu \mathrm{L}$ PBS. The resulting cell pellets were then resuspended in $200 \mu \mathrm{L}$ RPMI-1640 medium with $20 \%$ FBS in a Petri dish under normal cell culture conditions. We cultured the collected tumor cells from this device at 1,3,5, and 7 days and imaged by a confocal laser scanning microscopy (Olympus X81).

\section{Recovered CTCs culture in vitro for ATP-TCA procedure}

Chemosensitivity testing was assessed in cultured CTCs using an ATP-TCA kit containing serum-free complete assay medium, digestive enzymes, and luciferin-luciferase reagent. An amount of $100 \mu \mathrm{L}$ cell suspensions (containing $5 \times 10^{6} \mathrm{CTCs}$ ) from cultured CTCs were added to each well of a 96-well polypropylene microplate. Single agents were tested at six different doses $(6.25,12.5,25,50,100$, and $200 \%$ ) of a standard test drug concentration (TDC). The TDC values were $13.8 \mu \mathrm{g} / \mathrm{mL}$ for paclitaxel (PTX), $20 \mu \mathrm{g} / \mathrm{mL}$ for cis-dichlorodiamine platinum (II) (DDP), $25 \mu \mathrm{g} / \mathrm{mL}$ for carboplatin, $25 \mu \mathrm{g} / \mathrm{mL}$ for gemcitabine, 10 $\mu \mathrm{g} / \mathrm{mL}$ for docetaxel (TXT), and $20 \mu \mathrm{g} / \mathrm{mL}$ for etoposide (VP-16). For each concentration, two wells were used as controls, one containing $100 \mu \mathrm{L}$ ATP inhibitor for maximum inhibition (positive control) and the other containing complete assay medium only (no drug, negative control). Plates were incubated for $5-6$ days at $37^{\circ} \mathrm{C}$ with $95 \%$ humidity in a $5 \% \mathrm{CO}_{2}$ incubator. Following incubation, the cells were lysed by the addition of $50 \mu \mathrm{L}$ ATP extraction reagents, and $50 \mu \mathrm{L}$ luciferin-luciferase reagents were added to each well. Measurements of luminescence were recorded using a microplate luminometer (Orion II; Berthold Diagnostic Systems, Bad Wildbad, Germany), and inhibition curves were established. The results were interpreted and compared using the parameters IC50, IC90 $\leq 100 \%$ TDC and IC50 $\leq 100 \%$ TDC and IC50 and Sensitivity Index (SI) (SI $=500$ - sum of \% tumor growth inhibition (TGI) at 200\%, 100\%, $50 \%, 25 \%, 12.5 \%$ and $6.25 \%$ TDC). Three categories of in vitro sensitivity were defined as follows: sensitivity, IC90 TDC; weak sensitivity, IC90 $<25 \%$ TDC or SI $\leq 250$; and resistance, $\mathrm{SI}>250$.

\section{Statistical analysis}

Analysis of variance and Student's $t$-test were used to perform the statistical analysis of the data. All experiments were done in triplicate. Data are represented as the mean \pm standard error of three independent experiments. A $P$-value of $<0.05$ was considered statistically significant.

\section{Results and discussion}

In order to optimize the operation parameters for CTC capture and release by the anti-EpCAM-coated Ap-P-SiNWS chips, the artificial CTC sample containing EpCAM-positive HCC827 NSCLC cells (200 cells/mL) and freshly purified human WBCs $\left(5 \times 10^{6} \mathrm{WBCs} / \mathrm{mL}^{-1}\right)$ in an RPMI medium was 
prepared. For the convenience of cell counting, HCC827 cells were prestained with DIO green fluorescent dye.

The capture performance of the Ap-P-SiNWS chip was first characterized with a $1.0 \mathrm{~mL}$ suspension of HCC 827 cells (100 cells $/ \mathrm{mL}$, in RPMI-1640 medium) at flow rates of $0.2,0.5,1.0,2.0$, and $4.0 \mathrm{~mL} / \mathrm{h}$. After rinsing and parallel staining of FITC-labeled anti-EpCAM (a surface marker for epithelial cells) and DAPI, the substrate-immobilized cells were imaged and counted under an upright fluorescence microscope (Olympus X81). The transparent PDMS chaotic mixer allows direct imaging analysis without dissembling the sandwiched devices. The results (Figure 3A) suggest that an optimal flow rate $(1.0 \mathrm{~mL} / \mathrm{h})$ was determined based on the observed cell-capture efficiencies. To test this substrate for repeated capture and release of cells, we performed multiple cycles of studies in sequence using HCC827 cells again. We observed a gradually attenuated cell capture/release performance (solid line in Figure 3B) with an increasing number of experimental cycles. We hypothesize that the capture agent, anti-EpCAM, could dissociate from the polymer brushes as a result of its thermally responsive conformation changes during the capture/release processes. To validate this hypothesis, we repeatedly conducted anti-EpCAM conjugation prior to cell capture/release studies. By doing so, the cell capture/release performances in new cycles were restored (the dashed line in Figure 3B). Further, three control studies using 1) biotin Ap-P-SiNWS, 2) anti-EpCAM-coated biotin Ap-P-Flat-Si (flat, no nanofeature), and 3) antiEpCAM-coated SiNWS were carried out in parallel with the Ap-P-SiNWS chips. The results shown in Figure 3C suggest that: 1) capture efficiency of anti-EpCAM-coated SiNWs $(88.6 \% \pm 3.9 \%)$ is similar to anti-EpCAM-coated biotinAp-P-SiNWs (as high as $91.3 \% \pm 3.2 \%$ ) and 2) aptamerpolymer functionalized SiNWS play an indispensible role in achieving the superb cell capture performance. To test the specificity of anti-EpCAM-coated Ap-P-SiNWS chip, three EpCAM-expressing cancer cells (such as HCC827, MCF87, and PC3) in contrast to low or absence EpCAM-expressing cells (such as HeLa, Jurkat, and WBCs) were examined in parallel. Summarized results in Figure 3D suggest that the anti-EpCAM-coated Ap-P-SiNWS chips were capable of specifically capturing EpCAM-expressed cancer cells and nonspecific capturing the absence EpCAM-expressing WBCs $(1,050 \pm 568)$. Parallel staining of FITC-labeled anti-EpCAM, Cy5-labeled anti-CD45 (a surface marker for WBCs), and DAPI allowed us to identify and enumerate CTCs and WBCs under the microscope (Figure 3E). In our device, nanostructured substrates such as SiNWS could significantly increase the cell capture efficiency by increasing the friction between cell membrane of CTCs and the substrate surface (Figure 3F). Finally, we tested the dynamic range of the anti-EpCAMcoated Ap-P-SiNWS chips using a series of artificial NSCLC CTC samples that were prepared by spiking PBS and healthy donor's blood with DIO-stained HCC 827 cells at densities of $10,50,200,400,600$, and 800 cells $/ \mathrm{mL}$. The results indicate that the devices exhibit sufficient performance (Figure S2) for handling clinical samples that normally have CTC density ranging from a few to hundreds of CTCs $\mathrm{mL}^{-1}$.

We attempted to optimize the performance of our CTC release system by sequential thermoresponsive releasing and enzyme digesting through the Ap-P-SiNWS incorporated microfluidic chamber at various conditions. To prepare the cell-release studies, cell suspensions containing both $\mathrm{HCC} 827$ cells $(200$ cells $/ \mathrm{mL})$ and human WBCs $\left(5 \times 10^{6}\right.$ cells $\left./ \mathrm{mL}\right)$ were generated in RPMI-1640 medium. An amount of $1.0 \mathrm{~mL}$ of the cell suspensions was first introduced into Ap-P-SiNWS chips at $32^{\circ} \mathrm{C}$ (temperature control by constant temperature heating platform), and then the device was placed in the $4^{\circ} \mathrm{C}$ refrigerator for 15 minutes, and the substrate-immobilized cells (prestained with DIO green fluorescent dye) were rinsed with $4{ }^{\circ} \mathrm{C}$ ice-cold PBS at $0.1,0.2,0.5,1.0$, and $2.0 \mathrm{~mL} / \mathrm{h}$ (Figure 4A). The results suggested that a flow rate at $0.5 \mathrm{~mL} / \mathrm{h}$ appeared to be the optimal to achieve the highest release efficiency (as high as 92.6\%). To determine a reasonable time required for achieving effective enzyme-induced cell release via enzyme treatment. Firstly, these devices were kept at $4^{\circ} \mathrm{C}$, and $200 \mu \mathrm{L}$ ice-cold PBS solutions containing Benzonase Nuclease (20 units/mL, EMD Millipore, Billerica, MA, USA; Figure S3) were introduced to individual Ap-P-SiNWS chip. Enzyme-induced cell-release studies were then conducted by placing the devices in a constant temperature heating platform $\left(32^{\circ} \mathrm{C}\right)$ for $5,10,20,30$, and 45 minutes. After the released cells were flushed out of the channels, the remaining cells in the devices were imaged and enumerated again. The data summarized in Figure 4B imply that after 10-minute enzyme digestion, $>92 \%$ of immobilized HCC 827 cells were specifically released, while $<4.5 \%$ of immobilized WBCs were nonspecifically released. The 10 minutes is optimal as the enzymatic treatment time point for cell-release. To understand how the spiked HCC 827 cell numbers affect the cell-release performance, cell-release studies were conducted using cell suspensions (containing 10-500 HCC827 cells and $5 \times 10^{6} \mathrm{WBCs}$ ) with the 10 -minute enzyme digestion time. The results summarized in Figure $4 \mathrm{C}$ suggest that the cell-release performance is independent from the spiked cell numbers under the optimized experimental parameters. 
A

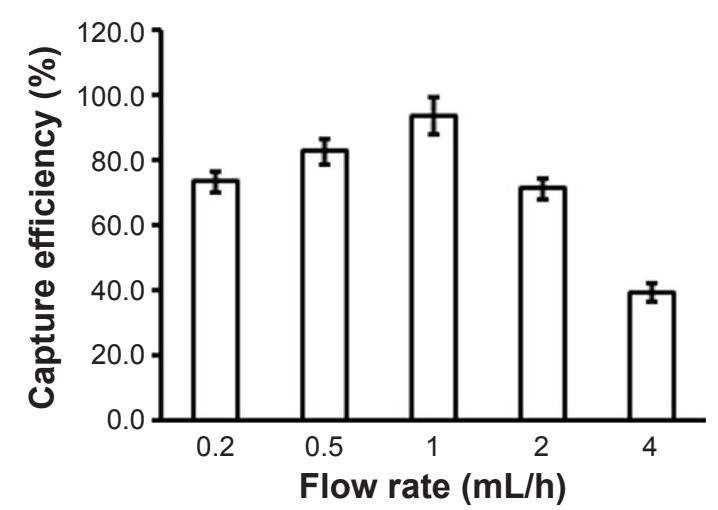

C

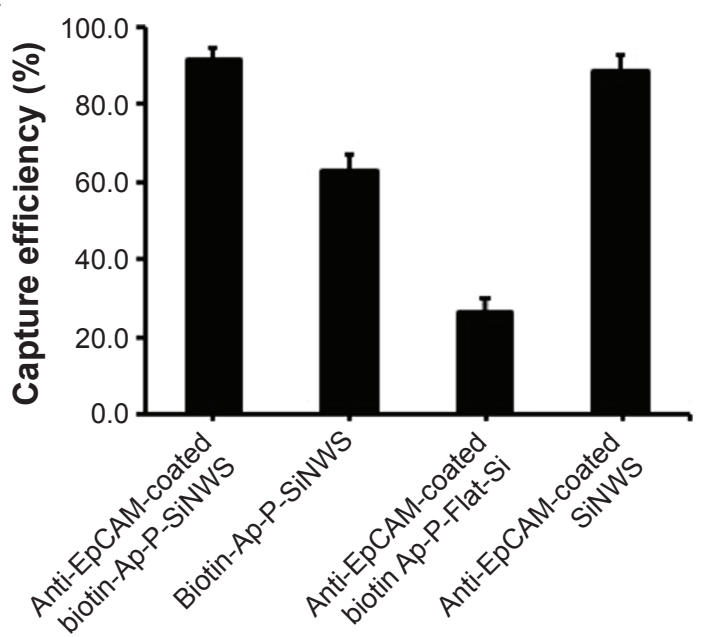

\section{Substrates}

\section{E}
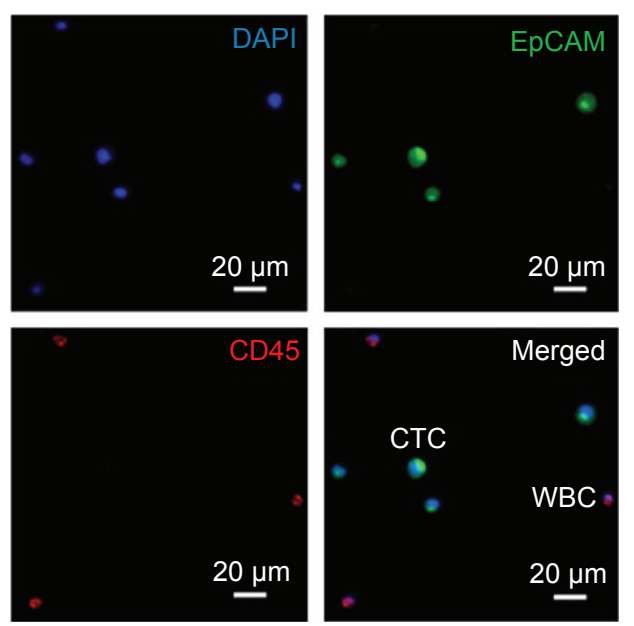

B

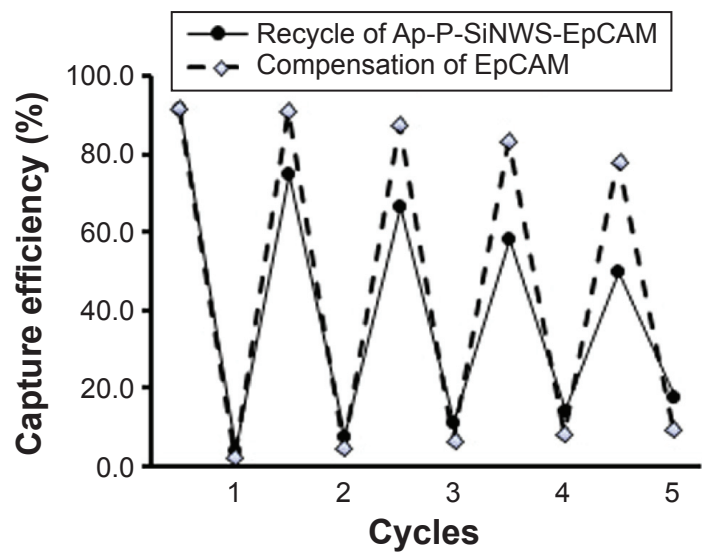

D

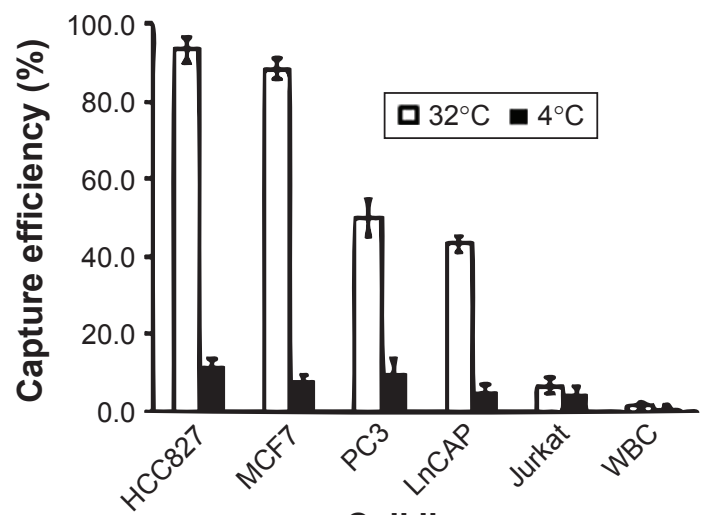

Cell lines

F

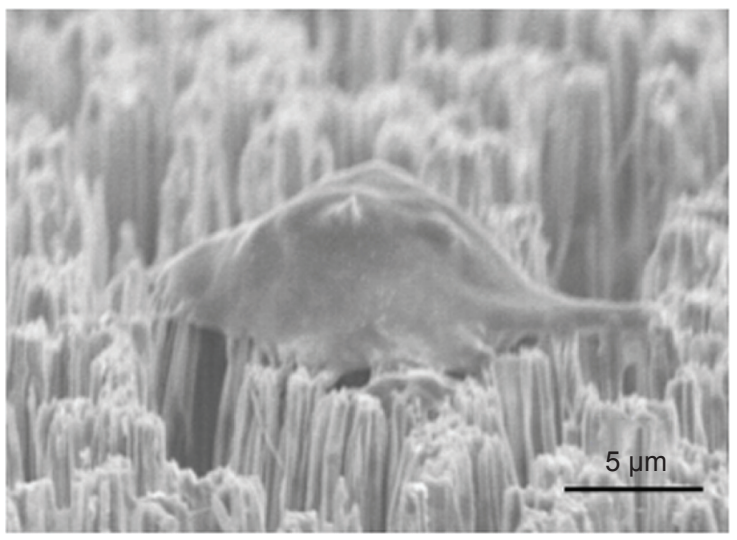

Figure 3 Cell-capture efficiency of the anti-EpCAM-coated Ap-P-SiNWS chip and identification of the captured CTCs.

Notes: (A) Cell-capture efficiency of the anti-EpCAM-coated Ap-P-SiNWS chip at flow rates of 0.2, 0.5, I, 2, and $4 \mathrm{~mL} / \mathrm{h}$. The error bars show the standard deviations $(\mathrm{n}=3)$. Cell suspensions $(1.0 \mathrm{~mL})$ containing HCC827 NSCLC cells (I00 cells $/ \mathrm{mL})$ were employed as a model system. (B) Cell capture/release performance of anti-EpCAMcoated Ap-P-SiNWS chip in sequential cycles studies with and without repeated anti-EpCAM conjugation. (C) In parallel with the anti-EpCAM-coated Ap-P-SiNWS chips, three control studies were conducted based on: I) biotin Ap-P-SiNWS, 2) anti-EpCAM-coated biotin Ap-P-Flat-Si (flat, no nanofeature), and 3) anti-EpCAM-coated SiNWS.

(D) Performance observed for capturing and releasing EpCAM-positive cell lines (such as HCC827, MCF7, and PC3) and EpCAM-negative cells (such as HeLa, Jurkat, and WBCs). (E) A three-color ICC method to identify substrate-immobilized CTCs (DAPI+/FITC+/Cy5-) from captured WBCs (DAPI+/FITC-/Cy5+). (F) A SEM image of a cell captured by the Ap-P-SiNWS chip.

Abbreviations: Ap-P-Flat-Si, aptamer-PNIPAM-flat-silicon; Ap-P-SiNWS, aptamer-PNIPAM-SiNWS; EpCAM, epithelial cell adhesion molecule; h, hours; PNIPAM, poly (N-isopropylacrylamide); SiNWS, silicon nanowire substrates; CTCs, circulating tumor cells; DAPI, 4'6-diamidino-2-phenylindole; FITC, fluorescein isothiocyanate; WBC, white blood cell; ICC, immunocytochemistry; SEM, scanning electron microscopy. 
A

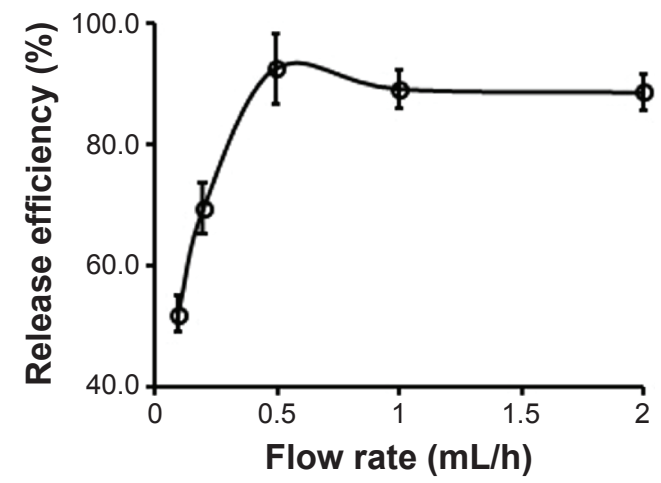

C

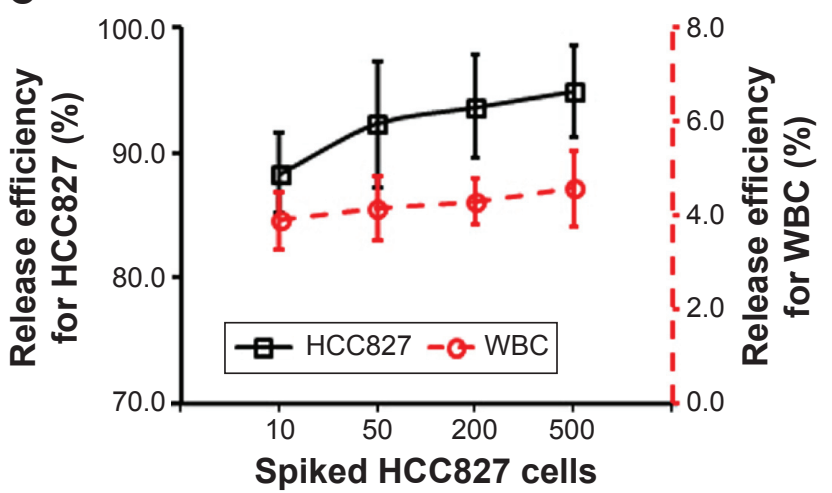

E

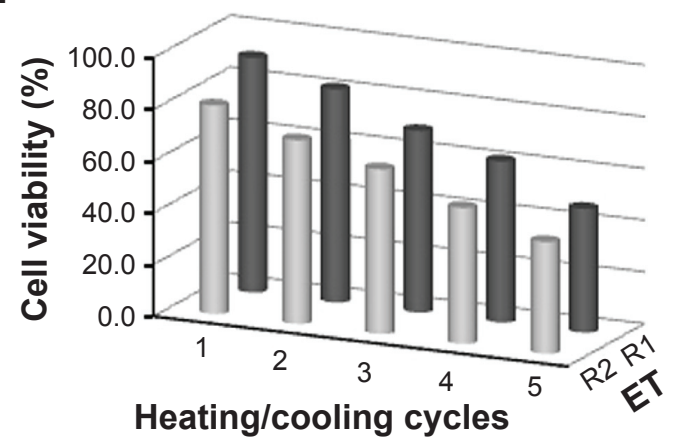

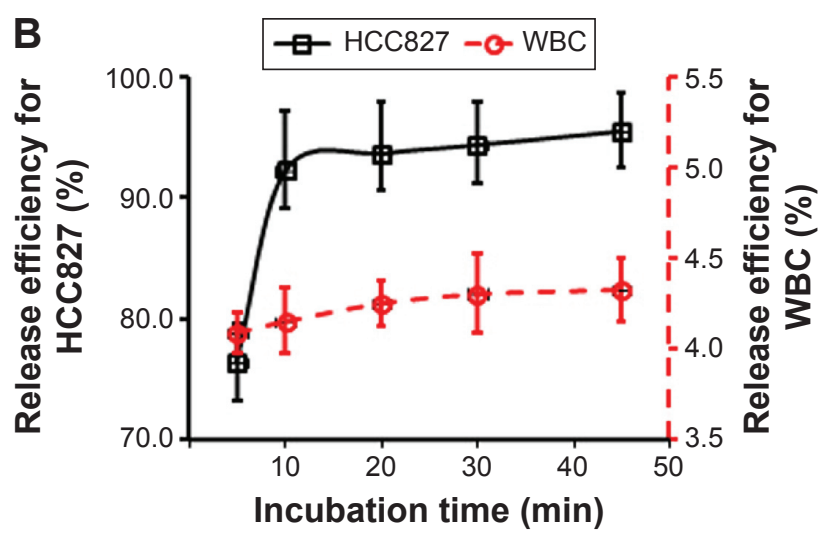

D

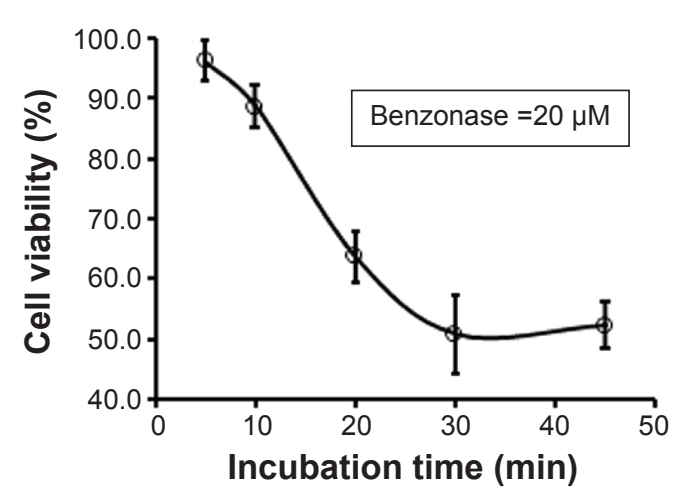

$\mathbf{F}$

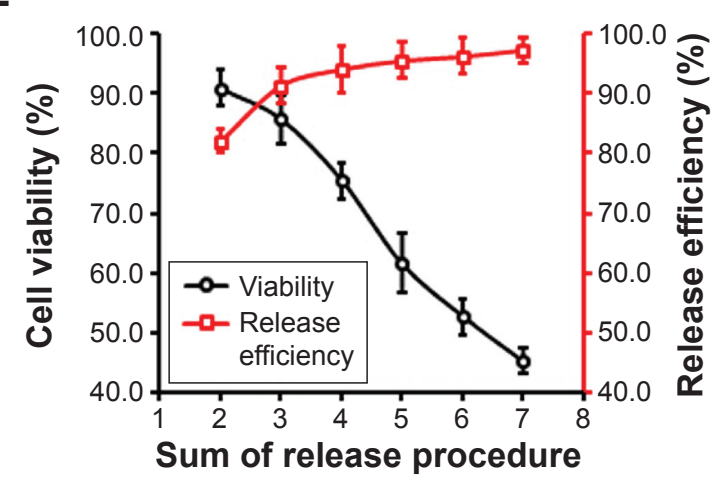

Figure 4 Cell-release efficiency and cell viability study of the anti-EpCAM-coated Ap-P-SiNWS chip.

Notes: (A) Quantitative evaluations of cell release performance of the anti-EpCAM-coated Ap-P-SiNWS chip at flow rates of $0.1,0.2,0.5, \mathrm{I}$, and $2 \mathrm{~mL} / \mathrm{h}$. The error bars show the standard deviations ( $n=3)$. (B) Time-dependent release efficiencies for both HCC827 cells and WBCs. (C) The release performance between spiked HCC827 cells and WBCs under different spiked HCC827 cell numbers. (D) Enzyme digestion time affected the viability of recovered cells. (E) Viability of recovered cells affected by different heating/cooling cycles and enzyme treatment rounds. (F) The relationship between release efficiency and cell viability of recovered cells under various experiment conditions (sum of release procedure means sum of heating/cooling cycles and enzyme treatment rounds).

Abbreviations: Ap-P-SiNWS, aptamer-PNIPAM-SiNWS; EpCAM, epithelial cell adhesion molecule; ET, enzyme treatment; h, hours; min, minutes; PNIPAM, poly (N-isopropylacrylamide); R, round; SiNWS, silicon nanowire substrates; WBC, white blood cell.

To determine the factors affecting viability of recovered cells by our device, we first tested the viability of recovered cells affected by different heating/cooling cycles. An amount of $1.0 \mathrm{~mL}$ of the cell suspensions (containing $500 \mathrm{HCC} 827$ cells and $5 \times 10^{6}$ WBCs) was first introduced into Ap-PSiNWS chips, and five cycles of heating/cooling process were conducted. Parallel tests allowed us to measure the recovered HCC 827 cells viability after every cycle by using an AO/ EB staining (a dual-fluorescence viability assay). The results summarized in Figure S4 suggest that recovered HCC827 cell viability is gradually decreased with the increasing of heating/cooling cycles. Further, to determine a reasonable enzyme treatment time required achieving ideal recovered cell viability by enzyme-inducing release. Initially, these model systems were kept at $4^{\circ} \mathrm{C}$, and $200 \mu \mathrm{L}$ ice-cold PBS solutions containing Benzonase Nuclease (20 units/mL, EMD Millipore) were introduced to individual devices. Enzyme-induced cell-release studies were then conducted 
by placing the devices in an incubator $\left(32^{\circ} \mathrm{C}\right)$ for $5,10,20$, 30 , and 45 minutes. After the released cells were flushed out of the channels, we measured the collected HCC 827 cell viability in different enzyme digestion time by $\mathrm{AO} /$ EB staining. The data shown in Figure 4D indicate that the viability of recovery HCC 827 cells is gradually attenuated with the increasing of enzyme digestion time. Furthermore, we tested the recovered cell viability affected by sequential heating/cooling process and enzyme treatments. An amount of $1.0 \mathrm{~mL}$ of the cell suspensions (containing 200 HCC 827 cells and $5 \times 10^{6} \mathrm{WBCs}$ ) was first introduced into Ap-P-SiNWS chips and heating/cooling process conducted. Then, we performed one or more heating/cooling cycles and carried out one or two round enzyme digestions. Parallel tests allowed us to measure the recovered HCC 827 cell viability after every point (such as one heating/cooling cycle and one round enzyme digestion, two heating/cooling cycles and one round enzyme digestion, etc) by using an $\mathrm{AO} / \mathrm{EB}$ staining. The results indicated that recovered $\mathrm{HCC} 827$ cell viability is gradually decreased with the increasing of heating/cooling cycles and enzyme digestion rounds, and one heating/cooling cycle and one round enzyme digestion appeared to be the optimal to achieve the highest viability (as high as 90.8\%) (Figure 4E). Finally, to investigate the relationship between release efficiency and cell viability of recovered cells under various experiment conditions, $1.0 \mathrm{~mL}$ of the cell suspensions (containing $200 \mathrm{HCC} 827$ cells and $5 \times 10^{6} \mathrm{WBCs}$ ) was first introduced into Ap-P-SiNWS chips, and then heating/ cooling processes and enzyme digestions were conducted. Parallel tests allowed us to measure the recovered HCC 827 cell viability and release efficiency of each sum of release procedure. The results implied that the relationship between release efficiency and cell viability of recovered cells under various experiment conditions is negative, and one heating/ cooling cycle and one round enzyme digestion could achieve the highest viability (90.8\%) and a high release efficiency (82.6\%) (Figure 4F).

To test the feasibility of culturing the recovered HCC 827 cells, we first performed viability studies on the HCC 827 cells in the cell suspension recovered from one cycle heating/ cooling and one round enzyme digestion of capture/release processes. The recovered HCC 827 cells were collected in an Eppendorf tube $(1.5 \mathrm{~mL})$. After the centrifugation, the cells were washed and resuspended with $100 \mu \mathrm{L}$ PBS. The resulting cell suspension was mixed with $100 \mu \mathrm{L}$ AO/EB working solution and immediately checked on the fluorescence microscope on a glass slide. The results suggest that the recovered HCC 827 cells exhibited $89 \%-93 \%$ viability (Figure 5A). For further cell culture, the recovered HCC 827 cells in suspension were first centrifuged and washed with $200 \mu \mathrm{L}$ PBS. The resulting cell pellets were then resuspended in $200 \mu \mathrm{L}$ RPMI-1640 medium with 20\% FBS in a 96-well plate placed in the cell culture incubator (HERA Cell $150,37^{\circ} \mathrm{C}, 5 \% \mathrm{CO}_{2}$ ). Figure 5B shows the cell morphologies of recovered HCC 827 cells cultured at day 1 , day 3 , day 5 , and day 7 .

The molecular analysis of CTCs provides important information to target therapy and an intriguing opportunity to obtain insights into tumor biology. ${ }^{29,30}$ In our studies, we demonstrated that the purity of HCC 827 cells could be increased to $90 \%$ by the sequential heating/cooling process and enzyme digestion. The scatter plot (Figure S5A) shows HCC 827/WBC distribution of the cell suspension obtained from the heating/cooling process and enzyme digestion studies $(n=5)$. To further examine the feasibility of performing molecular analysis on the recovered HCC 827 cells, we carried out a KRAS mutation analysis in recovered high purity HCC 827 cells by performing PCR amplifications, followed by Sanger sequencing (Figure S5B).

To validate the feasibility of chemosensitivity testing based on the recovered HCC827 cells, we performed chemosensitivity testing by using an ATP-TCA. We found that the SI values of PTX, DDP, carboplatin, gemcitabine, VP-16, and TXT are 152.2 $\pm 15.4,256.7 \pm 27.8,279.6 \pm 23.2$, $299.3 \pm 31.5,340.8 \pm 20.9$, and $398.6 \pm 26.3$, respectively. Overall, the sensitivity of recovered HCC 827 to the agents tested was in the following order: PTX $>$ DDP $>$ carboplatin $>$ gemcitabine $>$ VP-16 $>$ TXT (Figure 5C). The data show that PTX at 200\% TDC has the highest TGI (97.2\%), and the TXT at $6.25 \%$ TDC has the lowest TGI (8.3\%) (Figure 5D). So, our method can determine which agent and what concentration have the best chemosensitivity for recovered CTCs.

\section{Conclusion}

In summary, we have developed a novel CTC capture and release platform in which the thermoresponsiveness property of PNIPAM is exploited to specific capture and release of EpCAM-positive CTCs by heating/cooling process, and features of aptamer that can be digested by nuclease are used for specific releasing the captured CTCs by enzymatic treatment. The Ap-P-SiNWS can reduce the heating/cooling process cycle and enzyme treatment round and weaken the damage of recovered CTCs. So, the time-saving process is helpful to preserve the morphology and enhance the vitality of the recovered CTCs and is beneficial to the subsequent cell culture in vitro. We validate the feasibility of 


\section{A}

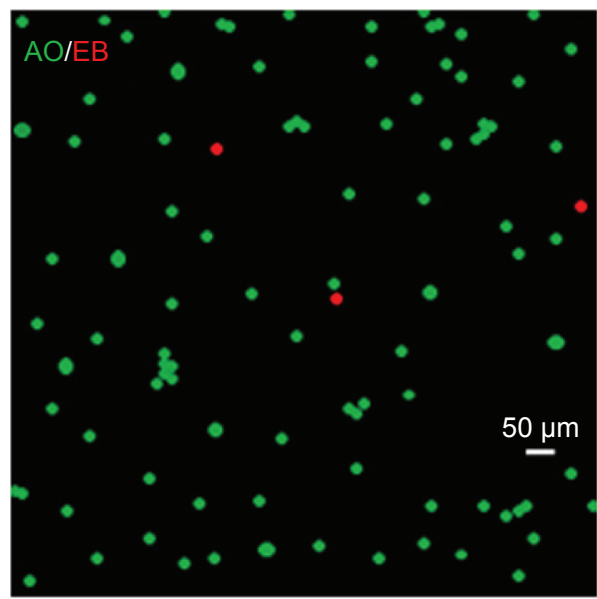

C

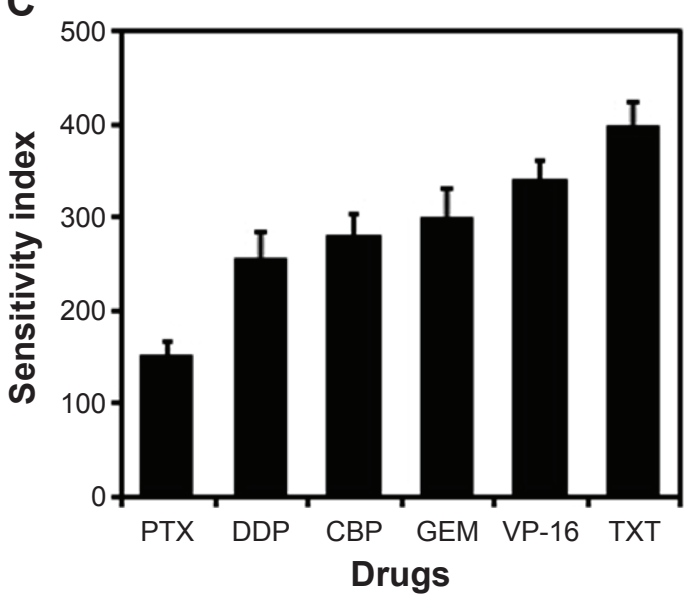

B
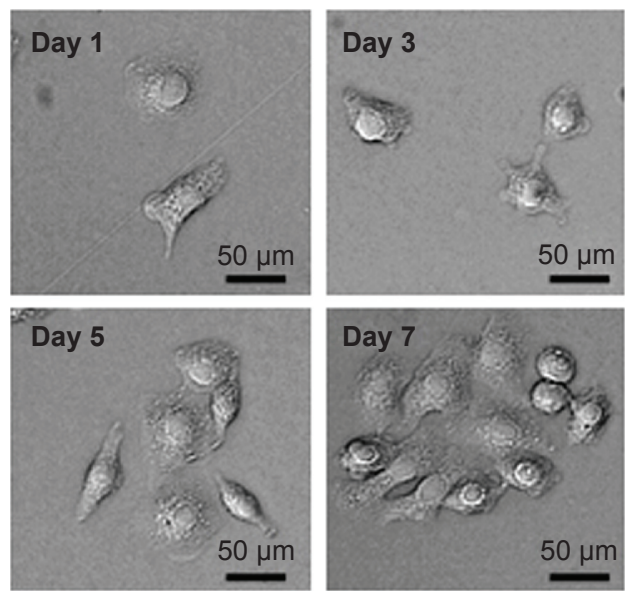

D

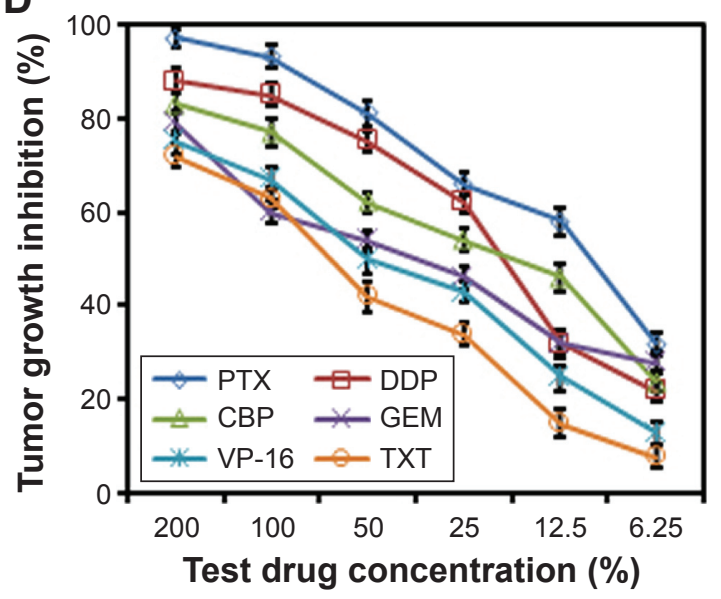

Figure 5 The viability test and culture study of the recovered $\mathrm{HCC} 827$, and the recovered $\mathrm{HCC} 827$ for in vitro chemosensitivity testing.

Notes: (A) Fluorescent images of recovered HCC827 cells by this method after AO/EB staining; AO-green staining implies live cells and EB-red staining implies dead cells. (B) Bright-field micrographs of the recovered HCC 827 cells that were cultured for I, 3, 5, and 7 days. (C) Frequency histograms (mean $+95 \%$ confidence interval) demonstrating the sensitivity indices among the chemotherapy agents tested. (D) Tumor growth inhibition curves demonstrate the sensitivity to the different chemotherapy agents based on culturing recovered CTCs. The error bars show the standard deviations $(n=3)$.

Abbreviations: AO, acridine orange; CBP, carboplatin; CTCs, circulating tumor cells; DDP, cis-dichlorodiamine platinum (II); EB, ethidium bromide; GEM, gemcitabine; PTX, paclitaxel; VP-I6, etoposide; TXT, docetaxel.

chemosensitivity testing based on the recovered HCC 827 cells using an ATP-TCA, and the results suggested that our method can determine which agent and what concentration have the best chemosensitivity for culturing recovered CTCs. The novel method capable of high effective capture and recovery of high viability CTCs will pave the way for chemosensitivity testing.

\section{Acknowledgments}

The authors thank the National Natural Science Foundation of China (81472748 and 81301084), Natural Science Foundation of Hubei (2014CFB155), and Applied Basic Research Program of Wuhan Science and Technology Bureau (2014062801011263) for supporting this work.

\section{Disclosure}

The authors report no conflicts of interest in this work.

\section{References}

1. Smith SC, Baras AS, Lee JK, Theodorescu D. The COXEN principle: translating signatures of in vitro chemosensitivity into tools for clinical outcome prediction and drug discovery in cancer. Cancer Res. 2010; 70(5):1753-1758.

2. Gasch C, Bauernhofer T, Pichler M, et al. Heterogeneity of epidermal growth factor receptor status and mutations of KRAS/PIK3CA in circulating tumor cells of patients with colorectal cancer. Clin Chem. 2013;59(1):252-260.

3. Yu M, Bardia A, Aceto N, et al. Cancer therapy. Ex vivo culture of circulating breast tumor cells for individualized testing of drug susceptibility. Science. 2014;345(6193):216-220.

4. Pantel K, Alix-Panabieres C. Circulating tumour cells in cancer patients: challenges and perspectives. Trends Mol Med. 2010;16(9):398-406.

5. Speicher MR, Pantel K. Tumor signatures in the blood. Nat Biotechnol. 2014;32(5):441-443

6. Bernards R, Weinberg RA. A progression puzzle. Nature. 2002; 418(6900):823

7. Hou S, Zhao H, Zhao L, et al. Capture and stimulated release of circulating tumor cells on polymer-grafted silicon nanostructures. Adv Mater. 2013;25(11):1547-1551.

8. Shen Q, Xu L, Zhao L, et al. Specific capture and release of circulating tumor cells using aptamer-modified nanosubstrates. Adv Mater. 2013;25(16):2368-2373. 
9. Wang C, Ye M, Cheng L, et al. Simultaneous isolation and detection of circulating tumor cells with a microfluidic silicon-nanowire-array integrated with magnetic upconversion nanoprobes. Biomaterials. 2015; 54:55-62.

10. Liu H, Li Y, Sun K, et al. Dual-responsive surfaces modified with phenylboronic acid-containing polymer brush to reversibly capture and release cancer cells. J Am Chem Soc. 2013;135(20):7603-7609.

11. Zhao L, Lu YT, Li F, et al. High-purity prostate circulating tumor cell isolation by a polymer nanofiber-embedded microchip for whole exome sequencing. Adv Mater. 2013;25(21):2897-2902.

12. Wang S, Wang H, Jiao J, et al. Three-dimensional nanostructured substrates toward efficient capture of circulating tumor cells. Angew Chem Int Ed Engl. 2009;48(47):8970-8973.

13. Went PT, Lugli A, Meier S, et al. Frequent EpCam protein expression in human carcinomas. Hum Pathol. 2004;35(1):122-128.

14. Stroock AD, Dertinger SK, Ajdari A, Mezic I, Stone HA, Whitesides GM. Chaotic mixer for microchannels. Science. 2002;295(5555):647-651.

15. Liu F, Cui Y, Wang L, et al. Temperature-responsive poly (N-isopropylacrylamide) modified gold nanoparticle-protein conjugates for bioactivity modulation. ACS Appl Mater Interfaces. 2015;7(21): 11547-11554.

16. Alvarez-Puebla RA, Contreras-Caceres R, Pastoriza-Santos I, Perez-Juste J, Liz-Marzan LM. Au@pNIPAM colloids as molecular traps for surface-enhanced, spectroscopic, ultra-sensitive analysis Angew Chem Int Ed Engl. 2009;48(1):138-143.

17. Li C, Alam MM, Bolisetty S, Adamcik J, Mezzenga R. New biocompatible thermo-reversible hydrogels from PNiPAM-decorated amyloid fibrils. Chem Commun (Camb). 2011;47(10):2913-2915.

18. Nash ME, Carroll WM, Nikoloskya N, et al. Straightforward, one-step fabrication of ultrathin thermoresponsive films from commercially available pNIPAm for cell culture and recovery. ACS Appl Mater Interfaces. 2011;3(6):1980-1990.

19. Nguyen HH, Payre B, Fitremann J, Lauth-de Viguerie N, Marty JD. Thermoresponsive properties of PNIPAM-based hydrogels: effect of molecular architecture and embedded gold nanoparticles. Langmuir. 2015;31(16):4761-4768.

20. Zhernenkov M, Ashkar R, Feng H, et al. Thermoresponsive PNIPAM coatings on nanostructured gratings for cell alignment and release. ACS Appl Mater Interfaces. 2015;7(22):11857-11862.
21. Tuerk C, Gold L. Systematic evolution of ligands by exponential enrichment: RNA ligands to bacteriophage T4 DNA polymerase. Science. 1990;249(4968):505-510.

22. Famulok M. Oligonucleotide aptamers that recognize small molecules. Curr Opin Struct Biol. 1999;9(3):324-329.

23. Coles DJ, Rolfe BE, Boase NR, Veedu RN, ThurechtKJ. Aptamer-targeted hyperbranched polymers: towards greater specificity for tumours in vivo. Chem Commun (Camb). 2013;49(37):3836-3838.

24. Guo J, Gao X, Su L, et al. Aptamer-functionalized PEG-PLGA nanoparticles for enhanced anti-glioma drug delivery. Biomaterials. 2011;32(31):8010-8020.

25. Oh SS, Lee BF, Leibfarth FA, et al. Synthetic aptamer-polymer hybrid constructs for programmed drug delivery into specific target cells. $J \mathrm{Am}$ Chem Soc. 2014;136(42):15010-15015.

26. Gao H, Qian J, Yang Z, et al. Whole-cell SELEX aptamer-functionalised poly (ethyleneglycol)-poly (epsilon-caprolactone) nanoparticles for enhanced targeted glioblastoma therapy. Biomaterials. 2012;33(26):6264-6272.

27. Neubauer H, Stefanova M, Solomayer E, et al. Predicting resistance to platinum-containing chemotherapy with the ATP tumor chemosensitivity assay in primary ovarian cancer. Anticancer Res. 2008; 28(2a):949-955

28. Bontempo D, Li RC, Ly T, Brubaker CE, Maynard HD. One-step synthesis of low polydispersity, biotinylated poly (N-isopropylacrylamide) by ATRP. Chem Commun (Camb). 2005(37):4702-4704.

29. Khoo BL, Lee SC, Kumar P, et al. Short-term expansion of breast circulating cancer cells predicts response to anti-cancer therapy. Oncotarget 2015;6(17):15578-15593.

30. Gazitt Y. Homing and mobilization of hematopoietic stem cells and hematopoietic cancer cells are mirror image processes, utilizing similar signaling pathways and occurring concurrently: circulating cancer cells constitute an ideal target for concurrent treatment with chemotherapy and antilineage-specific antibodies. Leukemia. 2004; 18(1):1-10. 


\section{Supplementary materials}

\section{Fabrication of PDMS Chaotic Mixer}

PDMS chaotic mixers were fabricated based on a soft lithographic approach. ${ }^{1}$ The patterned silicon master mold (or silicon replicate) was fabricated by a standard two-step photolithographic procedure. A negative photoresist (SU8-2100, Micro Chem Corp., Newton, MA, USA) was spin-coated with a $100 \mu \mathrm{m}$ thickness onto a 3 inches silicon wafer. After exposure to UV and further development, a serpentine fluidic channel with a rectangular cross shape (length $22 \mathrm{~cm}$ and width $1.0 \mathrm{~mm}$ ) was obtained. Another negative photoresist (35 $\mu \mathrm{m}$, SU8-2025, Micro Chem Corp.) was spin-coated on the same wafer. Prior to UV irradiation, the mask was aligned (Karl Suss America Inc., Waterbury, VT, USA) to get an accurate alignment between the prior pattern and the pattern to be imprinted. The fabricated pattern contained ceiling "ridges" that promote chaotic mixing effect in the fluid channel. The mold was then exposed to trimethylchlorosilane vapor for 2-3 min and then transferred to a Petri dish. To prepare a $6 \mathrm{~mm}$ thick chip, a well-mixed PDMS prepolymer (GE Silicones, Waterford, NY, USA; RTV 615 A and B in 10 to 1 ration) was poured into the mold and kept in an oven at $80^{\circ} \mathrm{C}$ for $48 \mathrm{~h}$. The PDMS chaotic were then peeled off from the mold, and two through-holes were punched at the fabric channel's ends for connection with the fluidic handler.

\section{Preparation of Biotin-Ap-P-SiNWS}

Lithographically patterned SiNWS were prepared by a standard photolithography and a chemical wet etching process. Photoresist (AZ 5214) was spin-coated onto a silicon wafer with $100 \mu \mathrm{m}$ thickness. After exposure of UV light and development, the silicon wafer was kept in etching solution containing deionized water, HF (4.6 M), and silver nitrate $(0.2 \mathrm{M})$. Then, the substrate was treated with boiling aqua regia $(3: 1(\mathrm{v} / \mathrm{v}) \mathrm{HCl} / \mathrm{HNO} 3)$ for $15 \mathrm{~min}$. The patterned photoresist on the silicon substrate was removed by rinsing with acetone and ethanol. After being washed with deionized water and then dried with nitrogen, the patterned SiNWS were obtained. Figure S1A shows a SEM image of a patterned SiNWS.

The surfaces of the lithographically patterned SiNWS were modified with APTES (1\% (v/v) in toluene) to have amine groups. The APTES-grafted SiNWS were reacted with 2-bromo-2-methylpropionyl bromide $(9.1 \mathrm{~mL}, 72 \mathrm{mmol}$, and atom transfer radical polymerization (ATRP) $)^{2,3}$ initiator in the solution of dichloromethane $(200 \mathrm{~mL})$ and triethylamine (10 $\mathrm{mL}, 72 \mathrm{mmol})$. Then, NIPAM were polymerized on the surface of the ATRP initiator conjugated SiNWS. The molecular weight of these polymer brushes was measured as $4600 \mathrm{~g} / \mathrm{mol}$ and the thickness was estimated as $14 \mathrm{~nm}$. Then, the PNIPAM-SiNWS was treated with $40 \mu \mathrm{M}$ biotin-Aptamer in Tris- $\mathrm{HCl}$ buffer (10 mM, pH 7.5, containing $\mathrm{MgCl}_{2}, 5 \mathrm{mM}$ ) at room temperature for $1 \mathrm{~h}$, and washed with $200 \mu \mathrm{L}$ PBS for three times, and stored at $4^{\circ} \mathrm{C}$ refrigerator. Figure $\mathrm{S} 1 \mathrm{~B}$ shows a SEM image of a patterned biotin-Ap-P-SiNWS.

\section{Examining the dynamic range of the optimized anti-EpCAM-coated Ap-P-SiNWS chips}

Figure S2 was obtained after we completed all the optimization studies shown in Figure 3, with the intention to demonstrate the dynamic range of the optimized Ap-P-SiNWS Chips. Two sets of artificial CTC samples were prepared by spiking different numbers $(10,50,200,400,600$, and 800$)$ of HCC 827 cells into $1.0 \mathrm{~mL}$ blood (from healthy donor) or PBS. The results indicate that the Ap-P-SiNWS Chips exhibit sufficient cell-capture efficiency (ranging from 73.2
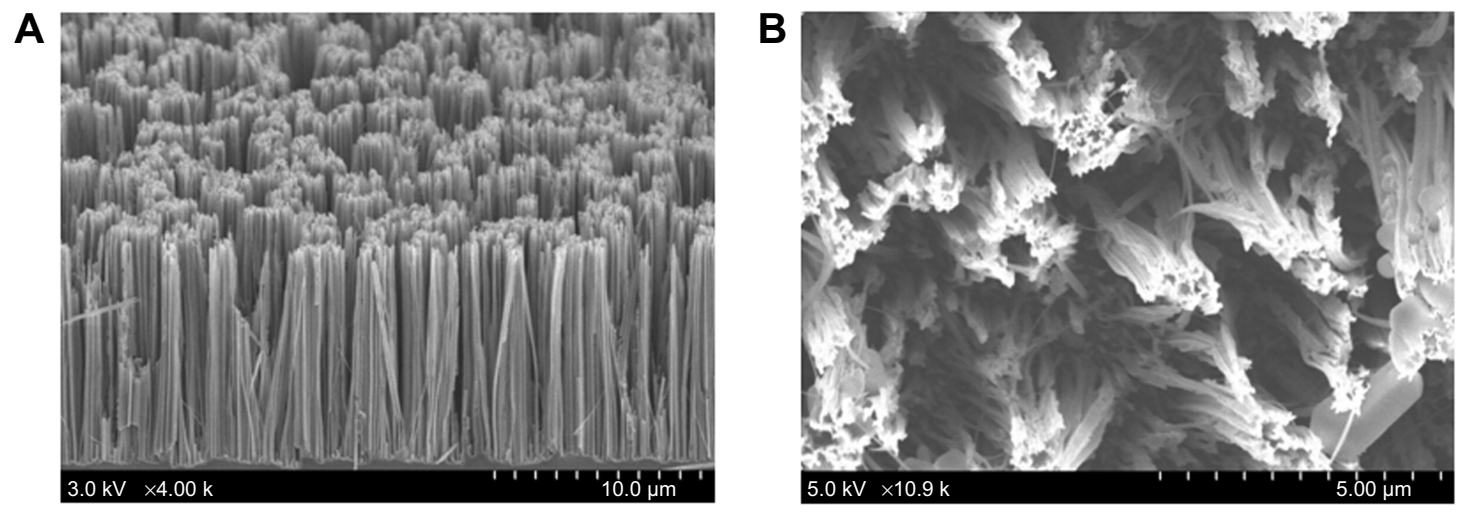

Figure SI SEM image of a patterned SiNWS (A). SEM image of biotin-aptamer-PNIPAM growth on SiNWS (B).

Abbreviations: PNIPAM, poly ( $\mathrm{N}$-isopropylacrylamide); SEM, scanning electron microscopy; SiNWS, silicon nanowire substrates. 


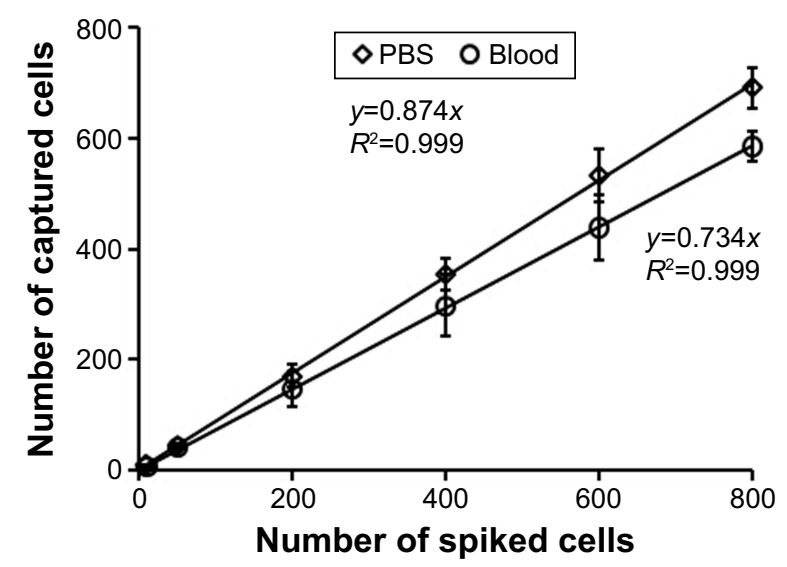

Figure S2 Dynamic ranges of the anti-EpCAM-coated Ap-P-SiNWS chips using a series of artificial NSCLC CTC samples that were prepared by spiking PBS and healthy donor's blood with DIO-stained HCC827 cells.

Abbreviations: Ap-P-SiNWS, aptamer-PNIPAM-SiNWS; CTC, circulating tumor cell; DIO, 3,3'-dioctadecyloxacarbocyanine; EpCAM, epithelial cell adhesion molecule; PBS, phosphate-buffered saline; PNIPAM, poly (N-isopropylacrylamide); SiNWS, silicon nanowire substrates.

to $91.6 \%$, Figure S2) for handling clinical samples that normally have CTC density ranging from a few to hundreds CTCs $\mathrm{mL}^{-1}$.

\section{Optimization of Benzonase concentration that allows effective release of HCC827 cells in PBS}

These optimization studies were conducted before the studies (summarized in Figure 4A) in order to determine a reasonable Benzonase concentration that allow for effective release of HCC827 cells in PBS. Artificial samples were prepared by spiking $200 \mathrm{HCC} 827$ cells into $1.0 \mathrm{~mL}$ of PBS solution, and were utilized to flow through the Ap-P-SiNWS Chips at $0.5 \mathrm{~mL} \mathrm{~h}^{-1}$. As indicated in Figure S3, the $20 \mu \mathrm{M}$ Benzonase

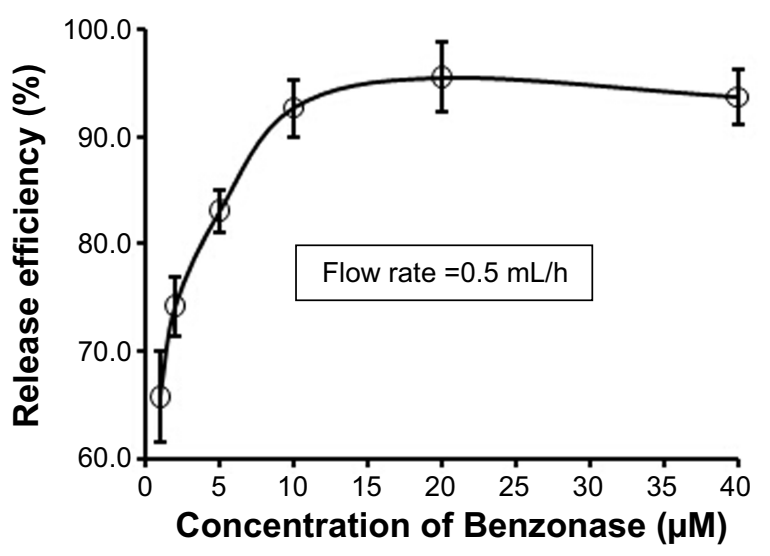

Figure S3 The cell release performance of the Ap-P-SiNWS chips as the foundation of the concentrations ( 1.0 to $40 \mu \mathrm{M}$ ) of Benzonase.

Notes: The $20 \mu \mathrm{M}$ of Benzonase concentration is determined for releasing the captured CTCs onto Ap-P-SiNWS.

Abbreviations: Ap-P-SiNWS, aptamer-PNIPAM-SiNWS; CTC, circulating tumor cell; h, hours; PNIPAM, poly (N-isopropylacrylamide); SiNWS, silicon nanowire substrates.

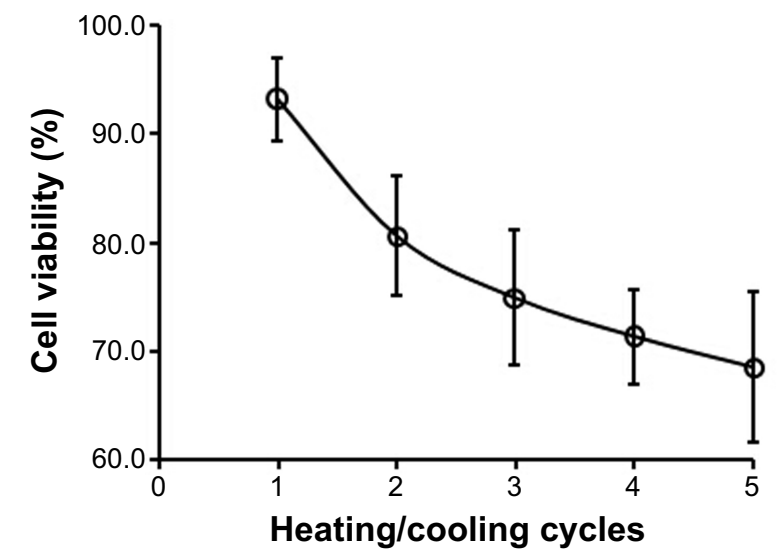

Figure S4 Heating/cooling cycles affected the viability of recovered cells.

will be enough for digestion the aptamer to promise satisfied release efficiency.

\section{Heating/cooling cycles affected the viability of recovered cells}

To determine the factors affect viability of recovered cells by our device, we first tested the viability of recovered cells affected by different heating/cooling cycles. $1.0 \mathrm{~mL}$ of the cell suspensions (containing $500 \mathrm{HCC} 827$ cells and $5 \times 10^{6} \mathrm{WBCs}$ ) were first introduced into Ap-P-SiNWS Chips and conducted five cycles heating/cooling process. Parallel tests allowed us to measure the recovered HCC 827 cells viability after every cycle by using an AO/EB staining (a dualfluorescence viability assay). The results summarized in Figure S4 suggest that recovered HCC827 cells viability is gradually decreased with the increasing of heating/cooling cycles.

\section{Mutation analysis on the HCC827 cells recovered from the sequential heating/cooling process and enzyme digestion}

To examine the feasibility of performing molecular analysis (Figure S5) on the recovered HCC827 cells, we were able to identify $\mathrm{KRAS}^{G 12 C}$ mutation in $\mathrm{HCC} 827$ cells recovered from the sequential heating/cooling process and enzyme digestion, by performing PCR amplifications, followed by Sanger sequencing. In contrast, only wild-type KRAS (present in WBCs) was detected from the initial artificial blood samples since the surrounding WBCs constitute the major cell population, making the $\mathrm{KRAS}^{G 12 C}$ mutation signal essentially invisible. The artificial blood samples were pretreated as described in references. ${ }^{4,5}$ Both artificial 


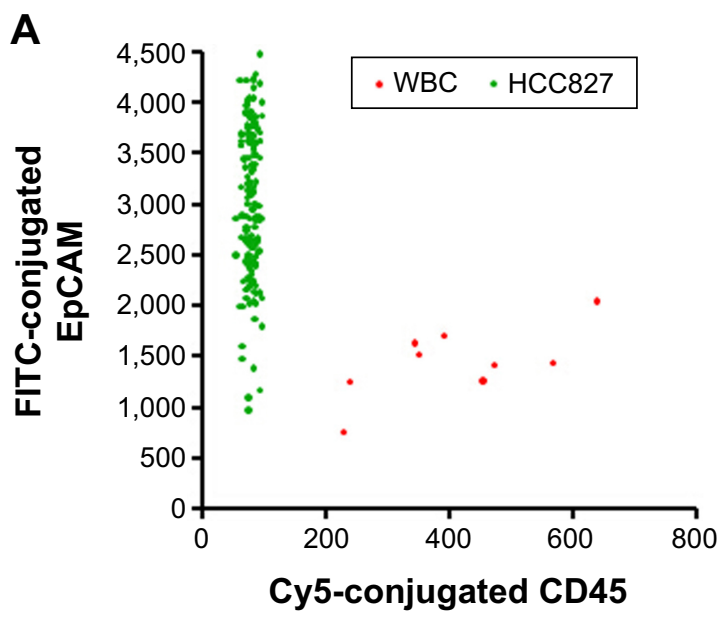

B

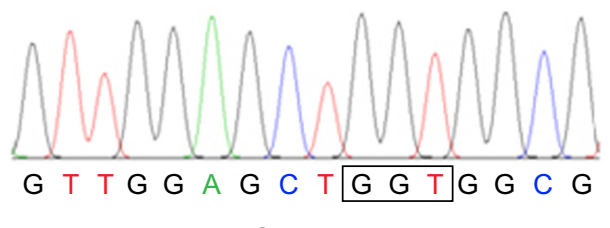

KRAS wild type

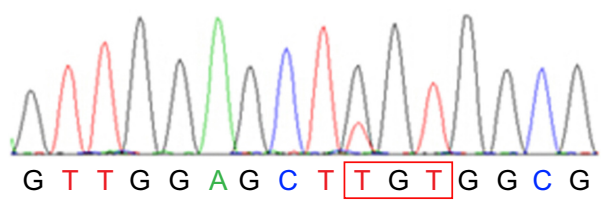

KRAS $^{\mathrm{G} 12 C}$ mutation

Figure S5 The purity study and molecular analysis of recovered HCC827 cells.

Notes: The scatter plot summarizes the HCC827/WBC cell distribution (with a purity of 93.8\%) in one of the cell suspensions obtained from the heating/cooling process and enzyme digestion study (A). Mutation analyses of KRAS on the HCC827 cells recovered from the heating/cooling process and enzyme digestion studies using the antiEpCAM-coated Ap-P-SiNWS chips (B).

Abbreviations: Ap-P-SiNWS, aptamer-PNIPAM-SiNWS; EpCAM, epithelial cell adhesion molecule; FITC, fluorescein isothiocyanate; PNIPAM, poly (N-isopropylacrylamide); SiNWS, silicon nanowire substrates; WBC, white blood cell.

blood samples and recovered HCC827 cells were then proceeded to extract gDNA for amplification using the GenomePlex $^{\circledR}$ Single Cell Whole Genome Amplification Kit (WGA2, Sigma-Aldrich). After further purification using QIAquick PCR Purification Kit (QIAGEN, Valencia, CA), $1 \mu \mathrm{L}$ of the whole-genome amplification (WGA) product was used for quality control by Gel Electrophoresis. Another $5 \mu \mathrm{L}$ WGA product was applied for KRAS (Primers: Forward CTACGCCACCAGCTCCAACTA, Reverse GTACTCATGTCAATGGTCAGAG) ${ }^{6}$ amplification by PCR. The sequence reads were aligned to the human reference genome using Novoalign V2.07.13 from Novocraft (http://www.novocraft.com). As indicated in Figure S4, $\mathrm{KRAS}^{G 12 C}$ mutation was clearly detected in the recovered HCC 827 cells from two rounds of specific capture and release rather than the whole blood samples.

\section{References}

1. Wang S, Wang H, Jiao J, et al. Three-dimensional nanostructured substrates toward efficient capture of circulating tumor cells. Angew Chem Int Ed Engl. 2009;48(47):8970-8973.

2. Bontempo D, Li RC, Ly T, Brubaker CE, Maynard HD. One-step synthesis of low polydispersity, biotinylated poly( $\mathrm{N}$-isopropylacrylamide) by ATRP. Chem Commun (Camb). 2005(37):4702-4704.

3. Xu FJ, Kang ET, Neoh KG. pH- and temperature-responsive hydrogels from crosslinked triblock copolymers prepared via consecutive atom transfer radical polymerizations. Biomaterials. 2006;27(14):2787-2797.

4. Maheswaran S, Sequist LV, Nagrath S, et al. Detection of mutations in EGFR in circulating lung-cancer cells. $N$ Engl J Med. 2008;359(4): 366-377.

5. Yung TK, Chan KC, Mok TS, Tong J, To KF, Lo YM. Single-molecule detection of epidermal growth factor receptor mutations in plasma by microfluidics digital PCR in non-small cell lung cancer patients. Clin Cancer Res. 2009;15(6):2076-2084.

6. Nadal E, Chen G, Prensner JR, et al. KRAS-G12C mutation is associated with poor outcome in surgically resected lung adenocarcinoma. J Thorac Oncol. 2014;9(10):1513-1522.

\section{Publish your work in this journal}

The International Journal of Nanomedicine is an international, peerreviewed journal focusing on the application of nanotechnology in diagnostics, therapeutics, and drug delivery systems throughout the biomedical field. This journal is indexed on PubMed Central, MedLine, CAS, SciSearch ${ }^{\circledR}$, Current Contents $₫ /$ Clinical Medicine,

\section{Dovepress}

Journal Citation Reports/Science Edition, EMBase, Scopus and the Elsevier Bibliographic databases. The manuscript management system is completely online and includes a very quick and fair peer-review system, which is all easy to use. Visit http://www.dovepress.com/ testimonials.php to read real quotes from published authors. 